\title{
Commentary: Pulling an entire lung out of a small incision-Video-assisted thoracoscopic surgical pneumonectomy, the final frontier in minimally invasive thoracic surgery
}

\author{
Juan Carlos Molina, MD, ${ }^{\mathrm{a}}$ and Moishe Liberman, $\mathrm{MD}, \mathrm{PhD}^{\mathrm{b}}$
}

\footnotetext{
From the ${ }^{a}$ Division of Thoracic Surgery, Department of Surgery, Centre Hospitalier de l'Université de Montréal, Montréal, Québec, Canada; and ${ }^{\mathrm{b}}$ C.E.T.O.C. (CHUM Endoscopic Tracheobronchial and Oesophageal Center), Montréal, Québec, Canada.

Disclosures: Authors have nothing to disclose with regard to commercial support.

Received for publication March 25, 2019; accepted for publication March 26, 2019; available ahead of print May $15,2019$.

Address for reprints: Moishe Liberman, MD, PhD, Centre Hospitalier de l'Université de Montréal, Centre de Recherche du CHUM, Room R04.402-1, 900 Rue Saint-Denis, Montréal, Québec, Canada H2X 0A9 (E-mail: moishe.liberman@umontreal.ca).

J Thorac Cardiovasc Surg 2019;158:267-8

$0022-5223 / \$ 36.00$

Copyright (c) 2019 by The American Association for Thoracic Surgery

https://doi.org/10.1016/j.jtcvs.2019.03.110
}

The advent of minimally invasive approaches for lobar and sublobar resections and the development of enhanced recovery pathways have allowed thoracic surgeons to improve the surgical experience of patients with lung cancer and decrease morbidity and costs without compromising oncologic outcomes. These outcomes have been reported extensively, and today there is consensus that videoassisted thoracoscopic surgical (VATS) lobectomy is the standard of care for patients with early stage non--small cell lung cancer. ${ }^{1}$ The expertise gained during the last 2 decades in terms of surgical technical and technological development has allowed us to expand the indications of VATS surgery to more complex operations, such as pneumonectomies, 2,3 anatomic segmentectomies, and sleeve bronchial resections. ${ }^{4}$ In this issue of the Journal, Yang and colleagues ${ }^{5}$ provide us with evidence to support extending minimally invasive approaches to whole-lung resections. This article provides early evidence that VATS pneumonectomy is at least as good as the open approach for patients with non-small cell lung cancer.

The study of Yang and colleagues ${ }^{5}$ includes more than 350 patients from 3 high-volume academic centers, 124 of whom underwent minimally invasive surgery. This is the largest VATS pneumonectomy series and the only multicenter series published to date. Yang and colleagues ${ }^{5}$ observed similar morbidity and mortality in the VATS and open groups, which held up even after multivariate adjustment; more importantly, they did not show any difference in overall survival. Furthermore, there were more lymph nodes resected and N2 stations dissected in the VATS group; however, this should not be interpreted by the reader to signify that VATS pneumonectomy is a superior oncologic procedure to thoracotomy. This study is retrospective, and there is no information regarding case selection for VATS

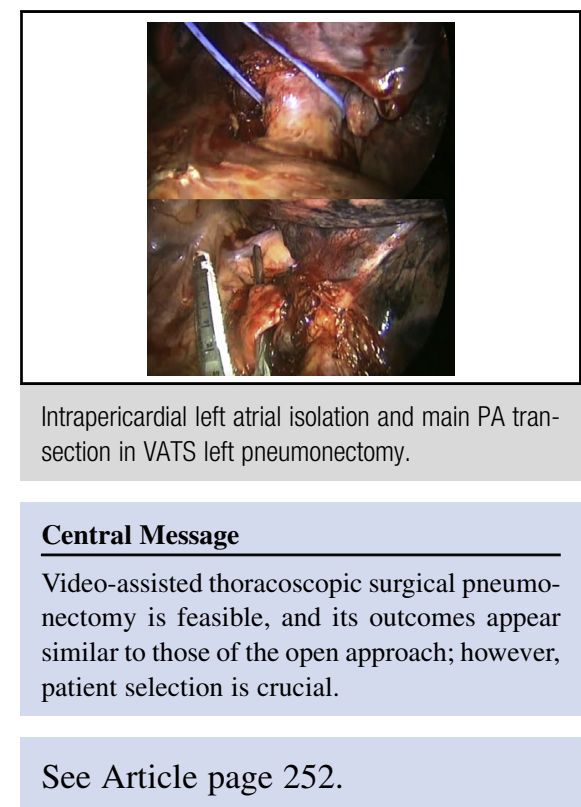

versus thoracotomy. These decisions are typically made on the basis of computed tomographic scan findings and proximity of the tumor to the mediastinum and the main pulmonary artery, as well as surgeon experience. It is impossible to ascertain from a retrospective cohort which criteria were used by each surgeon for each case to select one approach rather than the other. Moreover, during the long study period, the proportion of VATS pneumonectomies increased from less than $20 \%$ to more than $50 \%$, suggesting that the selection criteria changed with time, probably in response more to surgical expertise than to patient-related factors.

Yang and colleagues ${ }^{5}$ suggest that VATS pneumonectomy can be performed safely, with at least equivalent oncologic outcomes to those of thoracotomy. Even though we still need stronger evidence to support this conclusion, this study puts VATS pneumonectomy on the right track. This publication should encourage all of us to report our results and safely attempt minimally invasive approaches to oncologic surgery in our patients. VATS is not an operation, it is an approach, and with appropriate training, tools, patience, and surgical principles, it can be of significant benefit to patients. 
We need to remember that the best pneumonectomy is the one that is decided on after every attempt at a parenchymasparing procedure fails. Pneumonectomy should not be performed to avoid thoracotomy in patients who might benefit from airway bronchoplastic procedures (sleeve lobectomy or bronchoplasty) or vascular resection and reconstructions by thoracotomy. ${ }^{6}$

\section{References}

1. Vannucci F, Gonzalez-Rivas D. Is VATS lobectomy standard of care for operable non-small cell lung cancer? Lung Cancer. 2016;100:114-9.
2. Battoo A, Jahan A, Yang Z, Nwogu CE, Yendamuri SS, Dexter EU, et al. Thoracoscopic pneumonectomy: an 11-year experience. Chest. 2014;146: 1300-9.

3. Liu Y, Gao Y, Zhang H, Cheng Y, Chang R, Zhang W, et al. Video-assisted versus conventional thoracotomy pneumonectomy: a comparison of perioperative outcomes and short-term measures of convalescence. J Thorac Dis. 2016; 8:3537-42.

4. Caso R, Watson TJ, Khaitan PG, Marshall MB. Outcomes of minimally invasive sleeve resection. J Thorac Dis. 2018;10:6653-9.

5. Yang CF, Yendamuri S, Mayne NR, Battoo A, Wang H, Meyerhoff RR, et al. The role of thoracoscopic pneumonectomy in the management of non-small cell lung cancer: a multicenter study. J Thorac Cardiovasc Surg. 2019;158:252-64.e2.

6. Perentes JY, Zellweger M, Gonzalez M. Is pneumonectomy still necessary? J Thorac Dis. 2018;10:6414-7. 